\title{
Cerletti leitor de Montaigne: o ensino de filosofia como estímulo à pergunta
}

\author{
Cleber Duarte Coelho*
}

\section{Resumo}

Este texto objetiva apresentar algumas reflexões oriundas da prática de ensino na disciplina de Filosofia no Ensino Médio, bem como a experiência docente na disciplina Seminário de Ensino de Filosofia no curso de Licenciatura em Filosofia da Universidade Federal de Santa Catarina. Além disso, estabelecem-se algumas digressões sobre aquilo que se entende ser uma falsa dicotomia: formação para pesquisa versus formação para a docência. Sendo assim, apresenta-se Montaigne e Cerletti como incentivadores de uma pedagogia da pergunta, buscando ir além de uma experiência docente voltada para a mera reprodução técnica de conteúdos. Desse modo, entende-se que é preciso superar a exigência acrítica dos conteúdos filosóficos por parte dos alunos, sendo fundamental estimulá-los à formulação de perguntas e construção de uma postura reflexiva.

Palavras-chave: Filosofia. Ensino. Pergunta.

* Doutor em Filosofia pela Universidade Federal de Santa Catarina (UFSC). Professor do Departamento de Metodologia do Ensino, do Centro de Ciências de Educação, da Universidade Federal de Santa Catarina (UFSC). 


\section{Introdução}

Este texto tem por finalidade socializar algumas reflexões provenientes de nossa prática de ensino, exercida durante anos em escolas de Ensino Médio. Além disso, estabelecemos algumas digressões sobre aquilo que entendemos ser uma falsa dicotomia (bacharelado versus licenciatura), e também sobre nossa docência atual voltada para a formação de professores. Há três anos ministramos a disciplina Seminário de Ensino de Filosofia para aqueles que optam pela licenciatura presencial em Filosofia na Universidade Federal de Santa Catarina (UFSC), tarefa tão árdua quanto prazerosa.

Um dos objetivos primordiais da disciplina, ou mesmo de Metodologia de Ensino de Filosofia, é explorar as diversas possibilidades metodológicas ao trabalhar a Filosofia no Ensino Médio, além de tentar refletir sobre aquilo que deve caracterizar uma forma de conhecimento tão peculiar num contexto tão diferente daquele vivenciado dentro da academia.

Sabemos que são múltiplas as formas de tentar definir o que seja Filosofia. Como lidamos com quase três mil anos de história, deparamo-nos com dezenas de expressões referentes àquilo que filósofos e filósofas entenderam ser esse tipo de saber. No entanto, e lembrando que estamos pensando na Filosofia voltada para o Ensino Médio, parece-nos coerente afirmar que o conhecimento filosófico não lida, em última instância, com afirmações categóricas acerca disso ou daquilo. A Filosofia, e é fundamental que os adolescentes tenham essa referência, está envolvida com questões que permanecem em aberto, aporias da razão, temas-problema que vão às raízes geradoras de perguntas que se referem aos fundamentos dos conhecimentos. Esse processo não se estabelece por meio de mero opinionismo, mas mediante uma rigorosa análise conceitual que norteia criteriosamente um debate, tornando-o legitimamente filosófico. Tentando responder às questões através (ou a partir) da formulação de conceitos que pretendem dar conta de ampliar nossa leitura da realidade, mas que costumeiramente não esgotam as dúvidas existentes, porém geram outras tantas, num processo ininterrupto de investigação, fazemos Filosofia.

Nesse sentido, e partindo dos pressupostos acima referidos sobre a natureza da tarefa filosófica, podemos afirmar que a disciplina de Filosofia ministrada para crianças e adolescentes vai - ou deveria ir - na contramão daquele ensino meramente conteudista e tipicamente acrítico.

Percebemos, ao recordarmos de nossa vida discente no ambiente escolar e também da vivência docente nas diversas escolas de Ensino Fundamental e Médio onde atuamos, que a maioria das disciplinas ainda é regida pelo esquema pergunta pronta, resposta pronta.

O conhecimento escolar repassado aos alunos geralmente se limita a reproduzir (por isso, 
repassar) uma série de saberes reconhecidos historicamente como seguros e ditos verdadeiros, que ganham status de parâmetro curricular, sendo vistos como necessários ao progresso do estudante para o ingresso futuro na universidade e, quiçá, no mercado de trabalho. Não negamos a importância da absorção desses conhecimentos convencionados como seguros e tão necessários para a vida comum em sociedade. Entretanto, incomoda-nos o modo como são repassados, na maioria das vezes, sem reflexão crítica ou estímulo às perguntas sempre presentes nas mentes juvenis.

Essa preocupação com um ensino contextualizado, que leve em consideração a leitura de mundo dos alunos e seus contextos culturais, está presente, inclusive, em um documento oficial do governo federal, intitulado Orientações Curriculares Nacionais (OCNs):

A Filosofia é teoria, visão crítica, trabalho do conceito, devendo ser preservada como tal e não como um somatório de ideias que o estudante deva decorar. Um tal somatório manualesco e sem vida seria dogmático e antifilosófico, seria doutrinação e nunca diálogo. Isto é, tornar-se-ia uma soma de preconceitos, recusando à Filosofia esse traço que julgamos característico e essencial. Desse modo, cabe ensinar Filosofia acompanhando ou, pelo menos, respeitando o movimento do pensar à luz de grandes obras, independentemente do autor ou da teoria escolhida. (BRASIL, 2006, p. 35, grifo nosso).

Como vemos, as orientações curriculares oriundas do governo federal nos convocam a não trabalharmos no Ensino Médio de modo puramente voltado para a História da Filosofia em si e por si, mas convida-nos ao desafio de pensar conjuntamente com nossos alunos à luz desta História, correlacionando-a com nosso atual contexto cultural.

\section{A falsa dicotomia: bacharelado versus licenciatura}

Mas por que será que muitos professores de Filosofia no Ensino Médio reproduzem acriticamente a História da Filosofia? Muitos cursos de graduação voltados para a formação de professores direcionam, na metade do curso, seus acadêmicos a escolherem optar pelo bacharelado ou pela licenciatura. Supostamente - e isso impera no imaginário silencioso das universidades -, aqueles que optarem pelo bacharelado pretendem trabalhar como pesquisadores. Paralelamente, aqueles que optarem pela licenciatura buscam seu futuro nas salas de aula, atuando como professores. Essa divisão, extremamente ingênua (mostraremos os motivos), impede, muitas vezes, o acadêmico que opta pelo bacharelado de ocupar-se, também, em seus estudos, das questões pedagógicas que envolvem a metodologia e a prática de ensino, didática e o universo escolar, pois estes estudantes entendem que nunca precisarão lidar com questões pedagógicas. No entanto, não 
raro, muitos bacharéis graduados em Filosofia solicitam retorno para a universidade, objetivando fazerem a licenciatura, no intuito de obterem a certificação legal que os habilite a serem professores de Ensino Médio. Entretanto, não é incomum ver estes bacharéis reclamarem que as questões pertinentes ao ensino e à Educação são irrelevantes, pois eles são formados em Filosofia e querem discutir questões pertinentes à Filosofia. Ora, como podem ignorar a evidência de que uma das questões pertinentes ao pensar filosófico desde os gregos foi a Educação? Basta ler, por exemplo, $A$ República de Platão (mais especificamente o livro III da República) ou A Política de Aristóteles (os livros V a VIII tratam, entre outras questões, da Educação, sendo o livro VIII totalmente voltado para esta questão) para termos as evidências claras daquilo que estamos aqui dizendo. O próprio Werner Jaeger (1995), na Paidéia, atesta que os gregos, através de um esforço continuado, chegaram a uma fundamentação mais segura e mais profunda que a de nenhum povo da terra, do problema da educação.

Além disso, como pretende este bacharel, que vê na licenciatura um mal necessário, desenvolver seu papel nas escolas? Ministrará suas aulas para seus próprios botões, ciente de que seus alunos não estão à altura de sua inteligência para compreender a sabedoria inerente à sua exposição, desenvolvida em suas pesquisas? Há muito de enganoso nesta postura: aquele que vai atuar como educador, queira ou não, tem que esforçar-se para estar envolvido com as questões que envolvem o ser professor e o universo escolar. Se o indivíduo não quer de modo algum lecionar e entende que seu caminho é unicamente o da pesquisa, que seja honesto consigo e permita a quem de fato queira ser professor levar algo de significativo aos adolescentes.

No entanto, convém lembrar: esses bacharéis pesquisadores, que entendem serem as questões da Educação ocupação exclusiva dos pedagogos, não também de filósofos, parecem esquecer que, seguir a linha bacharelado-mestrado-doutorado, provavelmente lhes levará não só à pesquisa, mas também à sala de aula. Ao terminarem seu mestrado e doutorado farão concursos para atuarem como professores e pesquisadores: terão eles algum dia dispensado tempo para pensarem (e estudarem autores que discutem) sobre a importância dos mecanismos necessários à transmissão de seu saber? Sobre metodologias de ensino, didática, diferentes maneiras de abordar conteúdos em sala de aula?

É fundamental, portanto, perceber que todo bacharel necessita ocupar-se de questões pedagógicas, sobretudo os bacharéis em Filosofia, uma vez que muitos retornam para a universidade se vinculando à licenciatura, no intuito de obterem a habilitação para lecionarem nas escolas públicas de Ensino Médio. Além disso, se esses mesmos bacharéis seguirem o caminho da pós-graduação, provavelmente atuarão como professores em Faculdades, Centros Universitários e 
Universidades. Trabalhar também com pesquisa e não exclusivamente com a sala de aula, é algo que provavelmente só as universidades públicas lhes proporcionarão. Costumeiramente nas faculdades privadas, onde o professor é contratado como horista (recebe por hora/aula ministrada), não há qualquer tipo de incentivo da instituição para o desenvolvimento de pesquisas. O professor é contratado para ser unicamente professor, embora saibamos que não é possível ser um bom professor, sem ser pesquisador. Mas o fato é que este bacharel em Filosofia terá que mostrar habilidade em saber ministrar aulas, lidar com diferentes tipos de público-alvo, em diferentes cursos de graduação. Dificilmente alguém obterá êxito nessa empreitada se não estudar e ruminar, ao longo de sua formação, questões pertinentes ao agir pedagógico. Assim sendo, parece-nos evidente que o provável futuro profissional de um bacharel em Filosofia talvez perpasse a possibilidade da pesquisa, mas é quase certo que estará ligado à sala de aula, independentemente do nível de ensino. Estará este bacharel, de fato, atrelado às questões pertinentes à Educação? Quanto mais cedo perceber isso e ocupar-se também dessas questões em sua formação, tanto melhor será seu futuro profissional.

A mesma falsa dicotomia ocorre tantas vezes com aqueles que optam pela Licenciatura. " $E u$ só quero dar aulas" é uma frase que faz doer os ouvidos e o coração daqueles que entendem o sentido profundo da nobre missão de educar. Gostaríamos que todo licenciado em Filosofia tivesse a real noção da responsabilidade que seu papel de professor lhes trará. Afirmamos isso porque este licenciado falará de Filosofia a adolescentes, que estarão passando por um momento da vida onde se definem critérios de escolhas para o futuro, onde decisões quanto à profissão a ser escolhida precisam ser tomadas, onde valores podem ser questionados e ressignificados, grandes conflitos (envolvendo questões existenciais, afetivas, emocionais etc.) podem estar presentes. Supor que não é necessário primar por uma formação sólida, seja na leitura ou na escrita, seja no esforço para uma boa exposição oral de argumentos, supor que não é necessário buscar ser um exímio pesquisador, caracteriza-se como grande erro para o professor licenciado. Desse modo, como poderá preparar boas aulas se não souber pesquisar? Como poderá exigir de seus alunos qualidade na escrita e na leitura, na expressão oral de seus argumentos se ele mesmo, enquanto professor, não tiver bem alicerçado em sua formação esses quesitos? Nesse sentido, ressalta Drucker (2008, p. 291), que "O professor relevante em sua época terá de ser forçosamente um pesquisador".

Há quem se enverede pelos caminhos da licenciatura procurando justificar sua falta de comprometimento na própria formação, alegando que há descaso com a Educação no Brasil. Acusam os baixos salários pagos pelos governos estaduais, as más condições de manutenção e estrutura de grande parte das escolas, o desinteresse de muitos alunos. Sabemos que todos esses 
quesitos atrapalham a busca por um bom trabalho do professor e podem, evidentemente, dificultálo. No entanto, e isso precisar ficar claro, não há motivo suficiente neste mundo que justifique a falta de rigor e o desleixo de alguém que faz uma licenciatura para ser professor. Fazer a licenciatura de qualquer jeito, "empurrando com a barriga", somente para depois "pegar umas aulinhas porque trabalho para professor nunca vai faltar", é o tipo de atitude que só desmerece o magistério, tira a autoridade intelectual do professor diante dos alunos, e pior: impossibilita esses professores que foram mal formados (por opção própria) de conquistarem o respeito de seus alunos através do excelente trabalho que poderiam realizar. O descrédito que impera sobre o magistério nos dias atuais infelizmente existe, em grande parte, em função da postura desrespeitosa em relação à própria profissão, adotada por muitos de seus profissionais.

Do mesmo modo que um bom professor sabe quando seu aluno é interessado e quer de fato se dedicar a aprender, os alunos também sabem quando um professor prepara suas aulas e está seguro daquilo que está transmitindo. Essa segurança o profissional licenciado conquista não apenas se ocupando de questões didáticas e metodológicas em relação ao ensino, mas também pesquisando e preparando boas aulas sobre os conteúdos a serem ministrados. Em vista disso, fica evidente que todo bom licenciado tem que ser um bom pesquisador, porque ser professor implica no domínio desses saberes que serão tratados em sala de aula, e isso só se consegue com séria pesquisa.

Sabemos que em todas as áreas há profissionais que não se dedicam com a seriedade necessária à formação que escolheram. No entanto, estamos aqui falando de profissionais da Educação! A dedicação e seriedade nos estudos dos acadêmicos de muitas licenciaturas (evidentemente, sabemos que não podemos generalizar) tantas vezes se apresenta aquém daquilo que poderiam demonstrar. Muitos desses acadêmicos não percebem que optaram por uma profissão demasiado difícil: trabalhar em escolas (com todos os pormenores que envolvem a dura realidade do dia a dia escolar), ministrar conteúdos para crianças e adolescentes, de diferentes formações religiosas, diferentes princípios educacionais trazidos da própria família, em salas de aula que não raras vezes terão entre 40 e 45 alunos. Como exercer essa função sem estar devidamente preparado? Como exercer essa função sem em sua licenciatura ter se dedicado seriamente à leitura e à pesquisa? Como exigir leitura e pesquisa de nossos alunos adolescentes se nós mesmos não desenvolvemos estas habilidades quando cursamos nossa licenciatura? Ademais, e é preciso ressaltar isso, como poderemos ter critérios para corrigir, orientar, conduzir nossos alunos ao desenvolvimento destas habilidades, se nós mesmos professores não as possuímos? Não há escapatória: para ser bom professor, tenho que ser bom pesquisador!

Um acadêmico de Medicina que pretende ser cirurgião cardíaco deve ser lúcido quanto à sua 
responsabilidade, pois lidará com vidas. Do mesmo modo, compete ao acadêmico de licenciatura em Filosofia dar-se conta que lidará igualmente com vidas. Não abrirá o peito de ninguém para fazer uma intervenção coronariana, mas lidará com o intelecto de centenas de adolescentes em formação, e ainda com uma disciplina que muito tem a dizer sobre a relação do ser humano com o mundo que habita. Se não tiver noção, preparo e seriedade para assumir esse ofício com dedicação e esmero, com os requisitos fundamentalmente necessários para desempenhar bem seu papel, poderá naufragar a possibilidade de ofertar a esses adolescentes uma leitura filosófica do mundo, o que poderia enriquecer-lhes grandiosamente a existência.

Será possível, então, ser somente bacharel (leia-se, pesquisador), ou somente professor (leiase, profissional de sala de aula)? Parece-me pouco provável, pois percebemos que essa dicotomia existente entre bacharelado e licenciatura é falsa. Só pode ensinar bem quem tem suficiente leitura, amadurecidas reflexões sobre o conteúdo a ser ministrado: isso só se obtém com séria pesquisa. Só pode pesquisar bem e sobreviver fazendo essas pesquisas, o bacharel que necessita da sala de aula como requisito para sua atuação profissional, uma vez que dificilmente encontrará subsídios num país como o Brasil para atravessar a vida trabalhando exclusivamente como pesquisador em Filosofia. O pesquisador precisa da sala de aula, ainda que não por opção. Entretanto, uma vez em sala de aula, não pode simplesmente alegar que não obteve formação pedagógica. É sua responsabilidade buscar tal formação, pois além de pesquisador é também professor. Interessante seria percebermos que bacharelado e licenciatura se retroalimentam. Fragmentar bacharelado e licenciatura, como se o profissional fosse uma coisa ou outra, parece, de fato, demasiado ingênuo. É o que atestam as próprias Orientações Curriculares Nacionais (BRASIL, 2006):

Destacando ainda a mesma portaria, que o egresso do curso de Filosofia, seja ele licenciado ou bacharel, deve apresentar uma sólida formação em História da Filosofia, que o capacite a:

a) compreender os principais temas, problemas e sistemas filosóficos;

b) servir-se do legado das tradições filosóficas para dialogar com as ciências e as artes, e refletir sobre a realidade;

c) transmitir o legado da tradição e o gosto pelo pensamento inovador, crítico e independente. (BRASIL, 2006, p. 32, grifos nosso).

Em tempo, e corroborando com aquilo que expomos acima, o texto das OCN's é claro: sejamos bacharéis ou licenciados, necessitamos de uma sólida formação em história da Filosofia (requisito de bom pesquisador), e sabermos transmitir o legado da tradição (requisito de bom professor). Seriedade na própria formação, responsabilidade na transmissão de conteúdos. Bacharéis e licenciados terão que pesquisar e lecionar: quanto mais cedo perceberem isso, melhor para si mesmos e para seus alunos. 
Há quem não priorize uma sólida formação rigorosa em seus estudos. Assim, em poucos anos terão turmas diante de si, atuando como profissionais da Educação:

O currículo real inevitavelmente carrega o peso da história de formação de professores. Os "maus preparados" podem tomar como uma "cartilha" o material didático proposto para concretizar o currículo do ensino médio e, assim, correm o risco de adotar as indicações do material fornecido pela Secretaria da Educação ou de qualquer outro material didático - sem promover as devidas articulações nem as adaptações necessárias para pôr em execução os instrumentos da reflexão filosófica apropriados para a sua realidade de sala de aula. Por outro lado, professores muito bem preparados academicamente podem ser míopes para a realidade múltipla que se apresenta para cada turma e, assim, impor um trajeto filosófico inviável para o ensino médio. Ou seja, a efetivação ou não do currículo, assim como o despertar para a reflexão filosófica, para além do propagado aborrecimento ou desinteresse dos jovens para com a Filosofia, em grande medida, dependem da formação e da disposição dos docentes em olhar para suas turmas escolares. (GONÇALVEZ, 2011, p. 49).

Diante do exposto, podemos calcular o tamanho dos prejuízos causados àqueles que terão um professor de Filosofia que opta por estar alheio às questões fundamentais da Educação? Seria, então, um professor de Filosofia que ensina a responder, mas não incentiva o questionar?

\section{Educar para a pergunta}

Em nosso diálogo com aqueles que ministrarão a disciplina de Filosofia nas escolas, buscamos evidenciar a importância de ir além de um modelo pedagógico reprodutivista, reforçando a imprescindível caracterização da docência filosófica como pedagogia da pergunta. Se na maioria das disciplinas os alunos aprendem dar uma resposta já pronta e previamente apresentada, na disciplina de Filosofia, embora seja importante apreender os conceitos elaborados pelos pensadores e pensadoras da tradição, faz-se necessário não limitar o aluno a saber de cor a História da Filosofia e reproduzi-la pela simples memorização, sem um exercício crítico sobre os temas investigados. Assim, fundamental é estimulá-lo a pensar, levando em conta seu próprio contexto existencial e leitura de mundo, a partir dessas perguntas e respostas filosóficas formuladas ao longo da história e que o professor de Filosofia lhe apresenta.

Montaigne (1972, p. 82), nos seus Ensaios, lembra-nos sabiamente que:

Certamente tornaremos a criança servil e tímida se não lhe dermos a oportunidade de fazer algo por si. Quem jamais perguntou a seu discípulo que opinião tem da retórica, da gramática ou de tal ou qual sentença de Cícero? Metem-nas em sua memória bem arranjadinhas, como oráculos que devem ser repetidos ao pé da letra. Saber de cor não é saber: é conservar o que se entregou à memória para guardar. Do que sabemos efetivamente, dispomos sem olhar para o modelo, sem voltar os olhos para o livro. Triste ciência a ciência puramente livresca.

Embora seja um autor do século XVI, a passagem acima apresentada parece bem atual, já 
que, como é ressaltado, é preciso submeter os conhecimentos à apreciação do aprendiz, para que ele possa por si mesmo escolher aqueles que considera mais relevantes. Destacando a importância do educando saber mais apreciar os fatos do que simplesmente registrar, a pedagogia montaigniana pretende que tenhamos não um aluno com a cabeça cheia de conhecimentos memorizados, mas que saiba operacionalizar esses saberes apreendidos. As palavras de Montaigne (1972), nesse belíssimo ensaio intitulado "Da educação das crianças", servem de referência para aquilo que necessitamos como professores de Filosofia no Ensino Médio, pois encontramos subsídios para tentarmos livrar nossos alunos do analfabetismo funcional.

Assim, em nossa prática docente com os alunos do Ensino Médio, precisamos ir além do simples repasse de conteúdos. Compete-nos pensarmos criticamente o teor desses conteúdos, tornando a Filosofia instrumento de reflexão sobre a realidade por parte de nossos discentes. Do contrário, nos limitaremos a exigir-lhes mera reprodução de saberes historicamente constituídos, mas sem proporcionar aos estudantes aquilo que Montaigne (1972) considerava fundamental: tornar o próprio mundo um livro para a criança, e não só o conhecimento livresco das ciências. Conforme Silva (2007, p. 116), “Ao ler um filósofo, o importante não é repetir seus preceitos, mas reter seu espírito. Trate de assimilá-lo. Eis a bela metáfora utilizada por Montaigne".

Para o filósofo francês, é fundamental que o aprendiz expresse o sentido do que aprendeu, relacionando-o com a própria vida, e não simplesmente se valendo de um mecanismo mnemônico que, talvez, levasse o aprendiz a submeter-se cegamente à autoridade daquele que ensina. Afirma Montaigne (1972, p. 81), "Que não lhe peça conta apenas das palavras da lição, mas também do seu sentido e substância, julgando do proveito, não pelo testemunho da memória e sim pelo da vida".

Submeter nossos alunos a decorarem uma série de perguntas e respostas prontas para reproduzirem sem postura crítica e sem problematizações pessoais, sem que isso tenha a menor relevância para suas vidas, além da nota que irão obter, é algo que todo professor de Filosofia deve procurar superar. Ademais, esse tipo de postura pedagógica reproduz muito bem os interesses daqueles que objetivam tornar os estudantes futuros cidadãos bem governáveis, com baixo senso crítico e pouca capacidade de reflexão. Vivendo uma vida reificada e massificada, preenchida por entretenimentos vazios que a indústria cultural lhes impõe, prestaríamos um desserviço como professores de Filosofia aos nossos alunos se déssemos a esta disciplina a feição de erudição rebuscada e elitista, ou de mera reprodução acrítica de um saber já construído pela tradição.

Dessa forma, compete-nos levar as questões da História da Filosofia a serem pensadas de acordo com a própria realidade social e cultural em que nossos alunos estão inseridos, atraindo o seu interesse num esforço contínuo em evidenciar que essas questões não são alheias, mas, ao 
contrário, fazem parte de seus universos, porque são questões inerentes à espécie humana. Isso posto, Alejandro Cerletti (2008, p. 84, grifos nosso) coloca-nos:

Não haveria sentido que um problema filosófico fosse meramente "exposto" pelo professor, visto que, para que suas eventuais respostas adquiram significação para os alunos, estes deverão ter tornado próprio o problema (e não que, no melhor dos casos, se trate de uma inquietude somente do professor). Do contrário, não se tratará senão de respostas estranhas a perguntas não formuladas e, como sabemos, isso não leva para além da repetição do mesmo.

A perspectiva de Cerletti (2008) se volta para o desafio posto ao professor de tomar os problemas filosóficos como sendo seus, relacioná-los com o cotidiano, tendo a destreza de trabalhálos com seus alunos de forma viva e ativa. Compactuamos com essa perspectiva e entendemos que é um grande desafio para o professor fazer com que a Filosofia não seja "apenas mais uma disciplina”. Limitá-la à mera transmissão dos saberes compostos pela história da Filosofia, exigindo dos alunos sua reprodução acrítica, seria perder a oportunidade preciosa de inserir os adolescentes em uma visão filosófica do mundo permeada por muitas possibilidades de pensamento. Empresa inócua será, e isso nos parece evidente, esforçarmo-nos para construir uma base teórica se ela estiver dissociada de uma determinada prática. A Filosofia não pode ficar enclausurada no diletantismo intelectual daqueles que a fazem instrumento de ilustração (MATOS, 2013).

Sabemos das imensas dificuldades enfrentadas pelos professores de Filosofia no Ensino Médio: a falta de valorização por parte dos governos, excesso de aulas para tentar manter uma remuneração minimamente digna, problemas estruturais existentes em tantas escolas etc. No entanto, compete ao profissional manter, de acordo com suas possibilidades, um vigor imprescindível sempre presente, para tornar a aula uma oportunidade de contato com a Filosofia que seja significativo para si e para seus alunos. Nesse sentido, afirma novamente Cerletti (2008, p. 78, grifos nosso) que:

Devido a isso, aqueles que ensinam filosofia nunca poderiam ser simples técnicos, que apenas aplicam receitas ideadas por especialistas. Que, por economia profissional, por excesso de trabalho ou por qualquer outro motivo, um docente se repita em suas propostas - sem levar em conta os contextos e a particularidade de cada um dos cursos em que ensina - representa uma complicação que excede o sentido específico do ensino. Lamentavelmente, essa circunstância não é inabitual e constitui um dos aspectos mais delicados da reflexão sobre o ensino de filosofia, já que testemunha a irrupção das condições materiais do trabalho docente na qualidade do próprio ensino.

É nesse sentido que defendemos a necessidade de o professor ousar ter atitude filosófica, de não ter medo de acreditar que a Filosofia pode ser dinâmica e significativa para seus alunos, dandolhes subsídios para melhor pensarem sobre si mesmos e sobre a realidade cultural em que estão inseridos. Ensinar a teoria de um pensador sem experimentar vivamente as questões com que ele 
lidou para produzir suas investigações é, no melhor dos casos, uma orientação pedagógica apropriada a intenções de ensino dogmático, sem questionamento do valor daquilo que é ensinado (CUNHA, 2005).

\section{Professor filósofo: para concluir}

A "maneira" de ensinar dependerá, mais do que da aplicação de técnicas gerais ou supostamente neutras, da relação de cada professor com a Filosofia e do lugar que na aula se concede ao filosofar (CERLETTI, 2008). Portanto, que o professor tenha coragem para ser também filósofo na sua prática docente, oportunizando a seus alunos o espaço para o filosofar.

Este lugar apontado por Cerletti precisa aqui ser ressaltado! Aqueles que ministram (ou ministrarão) a disciplina de Filosofia no Ensino Médio precisam compreender que a Filosofia ensinada às crianças e aos adolescentes possui um viés metodológico extremamente diferenciado em relação àquele utilizado dentro das universidades. Na academia, grosso modo, enfatiza-se quase que exclusivamente o rigoroso domínio dos conceitos e dos sistemas filosóficos desenvolvidos ao longo da história, sem preocupações em relacionar esses conhecimentos com nosso cotidiano, nosso atual contexto social e cultural. No caso do Ensino Médio, a demanda é outra. Uma Filosofia puramente livresca nesse nível de ensino seria um desastre pedagógico anunciado. A Filosofia ministrada para os jovens, no contexto escolar, precisa falar diretamente à própria vida. Como atesta Severino (2009, p. 26-27):

E se, com relação aos pensadores do passado, não cabe exibi-los num museu de ideias antigas, com relação aos pensadores atuais não cabe expô-los num museu de ideias contemporâneas. Entendam-me bem: a mediação pedagógica exige a retomada e a exposição dessas ideias, não como uma peça de anatomia ou de museu, mas como uma dinâmica enérgica do pensar que problematiza nossa própria atualidade.

É por isso que defendemos ser a aula de Filosofia no Ensino Médio o momento propício para o estímulo constante à pergunta, à reflexão existencial, à compreensão de que as respostas categóricas que encontramos no mundo acerca das questões fundamentais são, no mínimo, suspeitas. Mas, para isso, é necessário seguir o sábio conselho de Montaigne (1972, p. 93): “Para voltar ao assunto, direi que o melhor é atrair a vontade e a afeição, sem o que se conseguem apenas asnos carregados de livros". Ou ainda, seguir a recomendação que nos dá Cerletti (2008, p. 87), que, certamente, leu os Ensaios (MONTAIGNE, 1972):

A Filosofia não é uma questão privada, ela se constrói no diálogo. Ensinar significa retirar a Filosofia do mundo privado e exclusivo de uns poucos para colocá-la aos olhos de todos, na construção coletiva de um espaço público. Por certo, em última 
instância, cada um escolherá se filosofa ou não, mas deve saber que pode fazê-lo, que não é um mistério insondável que apenas alguns atesouram. E, nisso, o professor tem uma tarefa fundamental em estimular a vontade.

Montaigne (1972) e Cerletti (2008) citam o estímulo à vontade como fundamental ao desenvolvimento de uma pedagogia filosófica. Para tanto, faz-se necessária uma postura, por parte do professor, de abertura ao diálogo, a oportunidade da dúvida e uma boa pedagogia da pergunta. Eis aí uma das tarefas fundamentais inerentes ao ensino de Filosofia no Ensino Médio.

\section{REFERÊNCIAS}

BRASIL. Secretaria de Educação Básica. Orientações Curriculares para o Ensino Médio. Ciências humanas e suas tecnologias. Vol. 3. Brasília: Ministério da Educação, Secretaria de Educação Básica, 2006. Disponível em: <goo.gl/U0im9e>. Acesso em: 30 set. 2015.

CERLETTI, Alejandro. O ensino de Filosofia como problema filosófico. Tradução de Ingrid Müller Xavier. Belo Horizonte: Autêntica, 2009.

CUNHA, José Auri. Filosofia na educação infantil: fundamentos, métodos e propostas. Campinas, SP: Alínea, 2005.

DRUCKER, Claudia. A base da distinção entre ensino e pesquisa no Brasil. In: KUIAVA, Evaldo A.; SANGALLI, Idalgo J.; CARBONARA, Vanderlei (Org.). Filosofia, formação docente e cidadania. Ijuí, RS: Editora da Unijuí, 2008.

GONÇALVES, T. O ensino de Filosofia na rede pública: a proposta curricular do Estado de São Paulo. In: GALLO, Silvio; GOTO, Roberto (Org.). Da Filosofia como disciplina: desafios e perspectivas. São Paulo: Loyola, 2011. p. 25-50.

JAEGER, Werner. Paidéia: a formação do homem grego. Tradução de Artur M. Pereira. São Paulo: Martins Fontes, 1995.

MATOS, Junot C. A formação pedagógica dos professores de filosofia. São Paulo: Loyola, 2013.

MONTAIGNE, Michel de. Ensaios. Tradução de Sérgio Milliet. São Paulo: Abril Cultural, 1972.

SEVERINO, Antônio Joaquim. Desafios atuais do ensino de Filosofia. In: TRENTIN, Rene; GOTO, Roberto (Org.). A Filosofia e seu ensino. São Paulo: Loyola, 2009.

SILVA, Divino José. Filosofia, educação das crianças e papel do preceptor em Montaigne. In: PAGNI, Pedro A.; SILVA, Divino José (Org.). Introdução à Filosofia da Educação: temas contemporâneos e História. São Paulo: Avercamp, 2007. p. 102-121. 
Cerletti lector de Montaigne: la enseñanza de la filosofía como estímulo a la pregunta

\section{Resumen}

Este artículo objetiva presentar algunas reflexiones oriundas de mi práctica de enseñanza en los años en que enseñé Filosofía en la Enseñanza Media, así como la experiencia docente en la disciplina de Seminario de Enseñanza de Filosofía en el curso de Licenciatura en Filosofía de la Universidad Federal de Santa Catarina-UFSC. Además, establecimos algunas digresiones sobre lo que entendemos ser una falsa dicotomía: formación para investigación versus formación para la docencia. Se presenta Montaigne y Cerletti como incentivadores de una pedagogía de la pregunta, buscando ir más allá de una experiencia docente orientada hacia la mera reproducción técnica de contenidos. De este modo, se entiende que es necesario superar la exigencia acrítica de los contenidos filosóficos por parte de los alumnos, siendo fundamental estimularlos a la formulación de preguntas y construir una postura reflexiva.

Palabras claves: Filosofía. Enseñanza. Pregunta.

\section{Cerletti reader Montaigne: the teaching philosophy as a stimulus to the question}

\begin{abstract}
This article aims to present some reflections derived from my teaching practice in the years when I taught philosophy in high school as well as teaching experience in the discipline of Philosophy of Teaching Seminar on Bachelor's Degree in Philosophy from Federal University of Santa Catarina. In addition, we set out some digressions about what we understand to be a false dichotomy: training for research versus training for teaching. Here Montaigne and Cerletti as supporters of a question of pedagogy, seeking to go beyond a focused educational experience for mere technical reproduction of content. Thus, we believe it is necessary to overcome the uncritical requirement of the philosophical content by the students and it is essential to encourage them to formulate questions and construct a reflective stance.
\end{abstract}

Keywords: Philosophy. Education. Question.

Enviado em: 08/08/2017

Versão final recebida em: 25/10/2017

Cleber Duarte Coelho

E-mail: rebelc2000@yahoo.com.br 